\title{
RELACIÓN ENTRE VIDA Y ESPÍRITU EN LA ANTROPOLOGÍA DE MAX SCHELER
}

\author{
Manuel SUANCES MARCOS
}

Abstract: The anthropological dualism soul-body, arising from Platonism and which culminates in Descartes, is elaborated by Max Scheler, in a new understanding of the concepts of life and spirit respectively. The German philosopher emphasizes the interdependence of both realities, despite their different natures, within the structural order of the human being. This interdependence has degrees of movement according to the thought process of Scheler. It is important to see that both realities gradually unite within a wide range of perspectives-metaphysical, gnosiological, axiological, psychological and cultural.

\section{Introducción}

Respecto al tema de la vida, una idea domina el pensamiento de Scheler: la vida, de acuerdo con la mentalidad del momento presente, ha irrumpido en la filosofía como una realidad con valor nuevo y propio que antes había sido ignorado y que ahora se hace imprescindible para explicar la realidad cósmica y humana. Referida al hombre, la vida se hace estructuralmente necesaria junto con el espíritu para llegar así a la comprensión de esa realidad básica que es la persona humana. La sensibilidad de Scheler variará en las etapas de su pensamiento según el matiz dado a cada uno de estos dos principios: vida y espíritu. En su primera etapa, subordinará aquélla a éste, aunque los haga igualmente necesarios. En su madurez, pondrá énfasis en la fuerza de la vida y en la impotencia del espíritu, aunque sigan teniendo estructuralmente la misma necesidad. Para seguir de cerca el plan- 
teamiento y desarrollo de este problema en Max Scheler, es preciso hacer un seguimiento del mismo a través de su obra y desde las diversas perspectivas filosóficas hasta desembocar en sus consecuencias en el orden cultural. Este artículo es el conjunto de esas diversas perspectivas en torno al problema.

1. Vida y espíritu como realidades esencialmente diferentes a la par que coprincipios esenciales del ser humano

¿Es el hombre un eslabón más en la esfera de los seres vivos o ésta termina con él para dar lugar a otro principio distinto a la vida, al ser psicofísico? ¿Cuál será entonces la relación entre ese nuevo principio y la vida? ¿Se soldarán de tal modo que configurarán una sola naturaleza? ¿Permanecerán unidos pero sin mezclarse dando lugar a una única actividad sustentada en un dualismo irreductible? Es aquí, en torno al puesto que le corresponde a la vida en el ser humano, donde ésta adquiere perspectiva, jerarquía y valor. Se trata de ver si en el hombre hay un principio distinto y superior a los grados del ser vivo, un principio que le convenga específicamente a él solo. Y aquí se bifurcan las posturas: unos quieren reservar la inteligencia al hombre negándosela a los animales superiores estableciendo así una diferencia esencial e irreductible entre los dos. Son los dualistas. Otros, en especial los evolucionistas, como Darwin, Lamarck y Köhler, niegan esa diferencia porque hacen partícipes de la inteligencia a los animales superiores; por tanto son partidarios de la teoría monista que late en la concepción del "homo faber". Scheler se define tanto frente al dualismo de los primeros como al monismo de los segundos. Frente a los primeros sostiene que la esencia del hombre está por encima de la inteligencia que éste comparte con los animales y, frente a los segundos, sostiene que la esencia del hombre marca un "quid" nuevo que hace de aquél un ser esencialmente distinto del ser vivo, del ser piscológico, postulando para él un principio metafísicamente nuevo:

«El nuevo principio que hace del hombre un hombre, es ajeno a todo lo que podemos llamar vida, en el más amplio sentido, ya en el psíquico interno o en el vital externo. Lo que hace del hombre un hombre es un principio que se opone a toda vida en generali un principio que, como tal, no puede reducirse a la "evolución natural de la vida", sino que, si ha de ser reducido a algo, sólo puede serlo al fundamento supremo de las cosas, 
o sea, al mismo fundamento del que también la "vida" es una manifestación parcial» ${ }^{1}$.

A ese principio los griegos lo llamaron «razón» y Scheler prefiere denominarlo "espíritu" porque este término no se circunscribe sólo al ámbito racional, sino que incluye también el amor y los actos emocionales que son tan espirituales como los puramente racionales. Visto el espíritu desde la trayectoria de los grados de vida, plantea una serie de problemas. La naturaleza, al llegar el hombre, da un salto en su proceso evolutivo rompiendo consigo misma o escindiéndose, a pesar de ella, al experimentar la aparición de un nuevo principio metafísico. Este principio, ¿estaba contenido potencialmente en la vida o no? Si lo estaba ¿por qué ha aparecido tan sólo en el hombre y no antes ni en otros seres? Si no lo estaba, ¿de dónde vino? ¿Tiene un origen histórico? ¿Baja al hombre en la medida que éste se aleja de la animalidad y se entrega a él? ¿Estuvo inserto en el hombre desde que éste apareció sobre la faz de la tierra? ¿Se deriva genéticamente de la vida o es totalmente ajeno a ésta? Scheler mantiene sin fisuras a lo largo de su pensamiento que el espíritu no se deriva de la vida; tal es la caracterización negativa de éste:

«Rechazamos plena y totalmente el biologismo metafísico, es decir, la concepción del principio mismo del mundo como "élan vital", "vida" "vida universal", "alma universal", etc., según lo ha defendido Bergson, Simmel, O. Lodge y otros. El "espíritu", el nous ni en cuanto "espíritu" cognoscente, intuitivo y pensante, ni en cuanto "espíritu" emocional y volitivo, es una "flor de la vida", una "sublimación de la vida"; ninguna especie ni forma de leyes noéticas se deja "reducir" a las leyes biopsíquicas de los procesos automáticos y (objetivamente) teleoclinos; cada uno de estos dos grupos es "autónomo"” ${ }^{2}$.

El espíritu es pues una realidad aparte de la vida. En este sentido, Scheler crítica al vitalismo, al positivismo y a los intentos de reducir el espíritu a un instinto biológico sofisticado. Especialmente se enfrenta a Nietzsche postulando un principio metafísico superior a la esfera vital, que tiene validez en sí mismo e independencia respecto a las cualidades vitales y por el que el ser humano adquiere un centro propio de gravitación. De forma semejante, el

1 Scheler, M. El puesto del hombre en el Cosmos, Buenos Aires, Losada, p. 54.

2 Scheler, M. Esencia y formas de la simpatia, Buenos Aires, Losada, p. 103. 
positivismo mantiene que el espíritu es algo nuevo pero exigido por la evolución misma de la vida y así será, junto con la inteligencia, el arma más precisa para el progreso vital. Tal sería la posición de Spencer. Pero por mucha utilidad que el espíritu tenga para el mundo de la vida, su naturaleza obedece a leyes distintas de las del progreso vital. El espíritu marca una ruptura en la evolución porque ni es previsible, ni está exigido por la condición de la vida, ni se deduce de ella. En ese sentido, el espíritu es algo gratuito e inasimilable a lo anterior.

Al centro de actos del espíritu, Scheler lo denomina "persona":

"Y denominaremos persona al centro activo en que el espíritu se manifiesta dentro de las esferas del ser finito, a rigurosa diferencia de todos los centros funcionales "de vida", que, considerados por dentro, se llaman también centros "anímicos" $"$.

La persona constituye así el lazo de unión ontológico de lo espiritual y lo vital en el hombre. $Y$ de esto se derivan consecuencias trascendentales para éste. Como ser vivo, el hombre está sujeto a las leyes reguladoras del mundo biopsíquico, las mismas que rigen la vida sub-humana. Mas, como ser espiritual, como persona, disfruta de una autonomía existencial frente a los lazos y presiones de su ser vivo. El ser espiritual no está entonces vinculado a lo orgánico y sus impulsos, sino que es libre frente a ellos.

Esta distinción de naturaleza entre vida y espíritu, a la par que su unión en la configuración del ser humano, es minuciosamente estudiada por Scheler desde diversas perspectivas filosóficas.

\section{El problema, desde el punto de vista metafísico}

¿Qué es el espíritu y cómo se define metafísicamente frente a la vida? Scheler es consciente de los desafueros que se han cometido con esta palabra y trata por eso de precisar su concepto y caracteres. El primero y más fundamental de ellos es su libertad por la que goza de autonomía existencial frente a los lazos y presión de lo orgánico:

3 Scheler, M. El puesto del hombre en el cosmos, p. 55. 
"La propiedad fundamental de un ser "espiritual" es su independencia, libertad o autonomía existencial $\longrightarrow$ la del centro de su existencia- frente a los lazos y a la presión de lo orgánico, de la "vida", de todo lo que pertenece a la "vida" y por ende también de la inteligencia impulsiva propia de ésta. Semejante ser "espiritual" ya no está vinculado a sus impulsos, ni al mundo circundante, sino que es "libre frente al mundo circundante", está abierto al mundo, según expresión que nos place usar. Semejante ser espiritual tiene "mundo" " 4 .

El mundo circundante del ser vivo comprende aquellos objetos que tienen un valor de símbolo para sus necesidades vitales; el esquema de la conducta animal está circunscrito por el círculo cerrado de los impulsos biológicos y de los objetos que dicen relación a aquellos. En este sentido también una parte del hombre participa de esos condicionamientos; el cuerpo humano tiene como correlato el mundo circundante. La corporeidad es el dato unitario de todos los fenómenos vitales. Pero el hombre trasciende esos lazos mediante la existencia de una característica que es independiente de las necesidades vitales tanto en su raíz como en su desarrollo. El ser humano escapa al aprisionamiento del mundo circundante mediante una técnica que consigue quitar a los objetos ese carácter de símbolos biológicos y llegar así a una mayor objetividad ${ }^{5}$.

Esto nos lleva a la segunda característica del espíritu: la objetividad. El espíritu puede elevar a la dignidad de objetos los centros de resistencia y atracción del mundo circundante. Puede aprehender la manera misma de ser de esos objetos sin la limitación que éstos experimentan por obra del sistema de impulsos:

«Espíritu es, por tanto, objetividad; es la posibilidad de ser determinado por la manera de ser de los objetos mismos. Y diremos que es "sujeto" o portador de espíritu aquel ser, cuyo trato con la realidad exterior se ha invertido en sentido dinámicamente opuesto al del animal" ${ }^{6}$.

El espíritu humano pues invierte el trato con la realidad que tiene el animal prescindiendo del estado fisiológico del organismo. Puede además reprimir los impulsos y modificar la objetividad de una cosa, modificación que vive como

4 Ibidem, p. 55.

5 Pintor Ramos, A. El humanismo de Max Scheler, p. 281.

6 Scheler, M. El puesto del hombre en el cosmos, p. 54. 
valiosa. Ello muestra que su conducta es fundamentalmente distinta de la del ser vivo, pues éste siempre que obra, lo hace movido por un estímulo perteneciente al mundo; lo que no sea atractivo para los impulsos, no es dado. El hecho de que el espíritu sea capaz de romper ese determinismo de la conducta animal y de objetivarla le hace esencialmente abierto y libre. El horizonte humano trasciende los intereses vitales y se abre a la contemplación objetiva de las cosas. Esta capacidad de objetivación se funda en la autoconciencia o conciencia de si que es un recogimiento del hombre en sí mismo por el que se convierte en dueño de su propia impulsividad. Y así el espíritu es objetividad de la propia constitución psicofísica humana. Por ello puede modelar libremente su vida. El animal está como en éxtasis ante su mundo ambiente, enclaustrado en el; no se puede alejar de él, vive psíquicamente en las cosas. Entre el animal y el medio hay una continuidad vital pero no como un todo, sino como una serie de puntos dislocados. $\mathrm{El}$ animal vive en lo exterior como si viviera en sí mismo y viceversa. Por tanto no se posee a si mismo, no tiene conciencia de sí, sino que vive como diseminado en su ambiente. Sólo el hombre que es un ser recogido en sí, vuelto sobre si mismo, exhibe la conciencia de si. Y esta capacidad de volver sobre si le dota de un carácter específico: convertir en objetiva su propia constitución fisiológica y psiquíca. Y esto hace factible la remodelación libre de su vida.

Scheler, en relación a esto, hace un elenco de categorías abstractas que el espiritu elabora sobre la base del material suministrado por su estructura psicofísica: son la sustancia y las formas vacías de espacio y tiempo. No tuvo tiempo de elaborar una teoría de las categorías acorde con la amplitud de su pensamiento metafísico. Su temprana muerte lo impidió. Sólo el hombre posee esas categorías con las que construye una imagen del mundo independiente de su organización psicofísica. El centro desde donde elabora esta objetivación del mundo no es parte de ese mundo espacio-temporal ni puede ser localizado en ningún lugar ni momento:

"Ahora bien; este centro, a partir del cual realiza el hombre los actos con que objetiva el mundo, su cuerpo y su psique, no puede ser "parte" de ese mundo, ni puede estar localizado en un lugar ni momento determinado. Ese centro sólo puede residir en el fundamento supremo del ser mismo. El hombre es, por tanto, el ser superior a si mismo y al mundos?

7 Ibidem, p. 65. 
Scheler, de acuerdo en esto con Kant, muestra la distinción y superioridad del espíritu sobre el yo, sobre la "psique».

Y arrancando de aquí, aparece la tercera característica del espíritu: la actualidad pura. Este centro de objetivación del mundo espacio-temporal no puede ser, a su vez, objetivado:

"Con esto hemos definido ya un tercero e importante carácter del espíritu. El espíritu es el único ser incapaz de ser objeto; es actualidad pura; su ser se agota en la libre realización de sus actos. El centro del espíritu, la persona, no es, por tanto, ni ser substancial ni ser objetivo, sino tan sólo un plexo $y$ orden de actos, determinado esencialmente, y que se realiza continuamente a si mismo en sí mismo" ${ }^{8}$.

Lo psíquico, pues, no se realiza a sí mismo; se compone de una serie de sucesos en el tiempo, contemplables desde el centro espiritual. Este centro sólo puede autocentrarse, no objetivizarse. La persona es la forma necesaria del ser espiritual, punto focal finito en que el espíritu se actualiza o centro por medio del cual el espíritu se manifiesta y actúa a través del hombre. Scheler insiste en la distinción de persona y yo psíquico. La persona no tiene nada de empírico ni es susceptible de aprehenderse empíricamente. Tampoco es sustancia ni ente sustancial; es simplemente la unidad concreta de todos los actos del espíritu en el hombre.

\section{El problema desde el punto de vista gnoseológico}

Desde una óptica fenomenológica, aborda Scheler ahora el tema de la relación del espíritu con el ser psicológico. Y así, atribuye a aquél un rasgo especifico que denomina acto de la ideación. Es éste un acto completamente distinto del de la inteligencia práctica. Un ejemplo de ésta sería preguntarme por el origen, por la causa de un dolor que tengo en un brazo y cómo puedo eliminarlo. Esto lo resolvería la ciencia positiva. Pero tomar este dolor concreto como caso particular de una realidad esencial supone preguntarse qué es el dolor en sí mismo, prescindiendo de éste que tengo aquí y ahora, y cómo debe estar constituido el fondo de las cosas para que sea posible el dolor en general. Esta es la ideación en palabras del propio Scheler:

$8 \quad$ Ibidem, p. 65-66. 
"Ideación es, por tanto, la acción de comprender las formas esenciales de la estructura del universo, sobre cada ejemplo de la correspondiente región de esencias, prescindiendo del número de observaciones que hagamos y de las inferencias inductivas. El saber que logramos de este modo es válido, con generalidad infinita para todas las cosas posibles que sean de esa esencia, prescindiendo totalmente de nuestros órganos sensoriales contingentes y de la índole y grado de su excitabilidad" ${ }^{9}$.

Por tanto idear el mundo, o mejor, el conocimiento ideatorio de las esencias del mundo es el acto fundamental del espíritu. Idear es aprehender la esencia de una cosa, aquello que hace que esa cosa sea precisamente esa y no otra. La esencia de una cosa es el modo íntimo e independiente de su ser. A la esencia le es indiferente la existencia. La esencia es el a priori del objeto, y lo que hace posible su existencia; pero en sí es extraespacial y extratemporal:

"En esta actitud se prescinde expresamente de la existencia real de las cosas, es decir, de su resistencia a nuestros impulsos y acciones, y con ello, justamente, de todo mero y contingente aquí-ahora-así, tal como nos es dado en la percepción sensorial. Por esto podemos también, en principio, efectuar un conocimiento de esencia en cosas de la fantasía. Por ejemplo, puedo incluso aprehender en un movimiento cinematográfico, también en un buen cuadro que representa un perro, elementos intuitivos últimos que pertenecen a la esencia (essentia) de un movimiento en general, de un "ser vivo" en general, y así sucesivamente» ${ }^{10}$.

Las esencias no existen sino que son meramente. La esencia no se agota en los hechos particulares que la encarnan sino que flota por encima de ellos como posibilidad sin límite de singularización. El espíritu, con el apoyo de la ideación, capta la esencia, o sea, el modo de ser ideal de los objetos o de los hechos:

«Esta facultad de superar la existencia y la esencia constituyen la nota fundamental del espíritu humano, en la que se basan todas las demás" ${ }^{11}$.

9 Ibidem, p. 68.

10 SCHELER, M. Cosmovisión filosófica en Metafisica de la libertad, Buenos Aires, Nova, 1960, p. 227.

11 SCHELER, M. El puesto del hombre en el cosmos, p. 69. 
De aquí que lo importante para el hombre no sea su saber acerca de los hechos; éstos como tales son un montón informe. Sólo el saber de las esencias captable en y a través de los hechos, es realmente un saber válido y universal. Pues las esencias son el priori del saber de los hechos. La esencia es lo a priori, el hecho, lo a posteriori ${ }^{12}$. Por eso sólo el valor de la esencia hace posible un saber de hechos. $\mathrm{El}$ animal, carente de espíritu, no tiene aptitud para separar esencia y existencia; conoce sólo ésta, no aquélla. He aquí las dos funciones del conocimiento de la esencia:

"Los conocimientos de esencia tienen una doble posibilidad de aplicación. Limitan para cada esfera de las ciencias positivas (matemática, física, biología, psicología, etc.). Los supuestos superiores de la respectiva esfera de investigación constituyen su "axiomática de esencias". Mas, para la metaffsica, estos conocimientos de esencia son, justamente, lo que Hegel de manera muy plástica llamó una vez "ventanas sobre lo absoluto" "13.

Este desatender la existencia en aras de la esencia equivale en el fondo, según Scheler, al acto de reducción fenomenológica propugnada por Husserl para el conocimiento o visión de las esencias. La operación de poner entre paréntesis el coeficiente existencial de las cosas para alcanzar su esencia constituye pues la raíz del proceso de lo que Scheler llama anulación ficticia del carácter de realidad, como camino hacia la perfecta ideación del mundo. El dice, en efecto, que, para saber cómo tiene lugar este acto de reducción fenomenológica de la realidad, es necesario saber en qué consiste propiamente nuestra vivencia de la realidad. Para Scheler, la existencia o realidad solamente nos es dada por la vivencia de resistencia que ofrecen las diversas realidades del mundo. Y esa resistencia nos viene dada por la conducta impulsiva respecto al mundo. En Idealismo-realismo, Scheler hace un recorrido en la historia del pensamiento viendo las aportaciones de los diversos filósofos a este punto de vista: Duns Scoto, Berkeley, Th. Reid, Jacobi, Fichte, Schopenhauer $y$, sobre todo, Maine de Biran. Scheler polemiza en este punto con Dilthey para quien la sensación no sólo es anterior a la vivencia de la realidad, sino que es su fundamento:

«Ante todo, Dilthey no ve con claridad que la resistencia vivida en general no es una experiencia sensible periférica, sino una auténtica experiencia

12 Gongora Perea, C., O.C., p. 57.

13 SCHELER, M. Cosmovisión filosófica, p. 229. 
central de nuestro impulso y de nuestra tendencia. Esa experiencia, la experiencia de resistencia, debe ser lo más rigurosamente distinguida de todas las otras sensaciones que la pudieran acompañar, v. gr., de todas las sensaciones del tacto y de las articulaciones..."

"Como mostraremos más adelante, puede darse también con objetos de la memoria y del pensamiento; por ejemplo, "el estado, que sólo se da en el pensamiento" opone resistencia a mi voluntad. La resistencia es, pues, una vivencia central del grado de mí "mismo", que en forma provisional determinaremos como un "centro impulsivo de vida" 14 .

La vivencia primaria de la realidad es pues una vivencia de resistencia que ofrece el mundo a nuestros impulsos y en general a nuestro impulso vital central. Esta vivencia precede a toda conciencia y representación. Para que la realidad se nos de, ha de existir siempre un movimiento impulsivo, bien sea de apetencia o de repugnancia. Ese movimiento encuentra un obstáculo o resistencia y, en la vivencia de tal obstáculo, se presenta lo real.

El acto de ideación consiste justamente en desrealizar, es decir, prescindir del carácter existencial de la realidad y llegar a la esencia de las cosas. Pero eso es una aniquilación ficticia de esa resistencia y de lo que ésta conlleva. Scheler, acorde en este sentido con Schiller, llama a este proceso eliminación de la angustia de lo terrenal que sólo desaparece en la región de las formas puras; es este uno de los ámbitos en que claramente se oponen vida y espíritu. Éste realiza la ideación, la inactualización del impulso afectivo, lo cual no es una destrucción para el ser humano, sino la condición para acceder a ese reino de esencias puras.

Aquí es donde Scheler plantea con toda hondura el significado del ascetismo, que no es una mera represión del impulso vital, sino un campo en que el espíritu se realiza y muestra la distinta naturaleza de ambos:

"El hombre es, según esto, el ser vivo que puede adoptar una conducta ascética frente a la vida — vida que le estremece con violencia-. El hombre puede reprimir y someter los propios impulsos; puede rehusarles el pábulo de las imágenes perceptivas y de las representaciones. Comparado con el animal, que dice siempre "si" a la realidad, incluso cuando la teme y rehu-

14 SCHELER, M. Idealismo-realismo, Buenos Aires, Nova, 1962, pp. 48 y 49; también en $E l$ puesto del hombre en el cosmos, pp. 35 y 70-71. 
ye, el hombre es el ser que sabe decir que no, el asceta de la vida, el eterno protestante contra toda mera realidad" 15 .

Las formas de dar cobertura a este ascetismo son numerosas; van desde la sublimación a la represión, desde la espiritualización al envilecimiento. Scheler conoce y critica a este respecto tanto el ascetismo cristiano que ha querido dar a éste un sentido que en si mismo no tiene, como el ascetismo naturalista de Nietzsche y Freud que ven en él un nuevo desarrollo humanista ajeno a una cualidad específica del espíritu. El ascetismo puede destruir al hombre no sólo por la represión incontrolada de los impulsos, sino por hacer de él un instrumento de potenciación del trabajo que termina por destruir también al hombre mismo. Los mecanismos de resentimiento que subyacen a estas actitudes son analizadas de forma magistral tanto como actitud de odio hacia el cuerpo como del odio hacia el espíritu ${ }^{16}$.

\section{El problema desde el punto de vista axiológico}

Pero el tema de la ideación y el consiguiente conocimiento de las esencias es sólo uno de los dos aspectos del ámbito de la fenomenología donde se pone de manifiesto la superioridad del espíritu sobre la vida. Y ciertamente no el más importante; aquél fue ampliamente desarrollado por Husserl. Scheler pone más empeño en dilucidar ese campo específico de las esencias que son los valores y, a través de él, esclarece una vez más la actividad del espíritu —esta vez enfocada desde la percepción emocional — frente a la actividad vital. Para Husserl las esencias son inteligibles, lógicas, captables mediante la intuición intelectual. Para Scheler hay esencias que no se captan por intuición intelectual. La mirada de Scheler no está dirigida hacia la conciencia pura, sino hacia la conciencia real que está inserta en lo vital. Se desvía pues del camino de Husserl para abordar ese mundo de los valores que puede ser ganado paulatinamente a través de la vida emocional. Este es el desvío de Scheler respecto a la fenomenología de Husserl. Para Scheler los valores son esencias alógicas, irracionales, como son lo bello, lo feo, lo noble, etc.; que son tan puras e indu-

15 SCHELER, M. El puesto del hombre en el cosmos, p. 72 y El saber y la cultura, pp. 45-46.

16 SCHELER, M. El resentimiento en la moral, Buenos Aires, Espasa-Calpe, 1938, pp. 115117. 
bitables como las esencias inteligibles. Al acto de captación de estas esencias lo llama Scheler intuición emocional o percepción sentimental:

«El percibir sentimental, el preferir, el amar y el odiar del espíritu tienen su propio contenido a priori, que es tan independiente de la experiencia inductiva como lo son las leyes del pensamiento. Y aquí como allí hay una intuición de esencias en los actos y sus materias, en su fundamentación y conexiones. En uno y otro caso existe la "evidencia" y la exactitud más estricta de la comprobación fenomenológica” ${ }^{17}$.

Por esta captación emocional de los valores, Scheler reivindica la excelsitud de la vida afectiva, poniendo de manifiesto que el carácter intuitivo de la conciencia lleva consigo una intencionalidad emocional. Este hecho emparenta a Scheler con San Agustín, Pascal y Bergson; para todos ellos existe una lógica del corazón con leyes propias que la razón no conoce. $Y$ eso mismo le lleva a oponerse a Descartes, Spinoza, Leibniz, Kant y el propio Husserl, para quienes la vida emocional es una etapa confusa de la vida intelectual.

El mundo de los valores es un mundo jerarquizado como el platónico de las esencias que se fundamentan en un valor último y personal que le da estructura y consistencia, como la idea de bien lo hacía en el mundo inteligible. Nuestro percibir emocional se va modulando en diversos grados correspondientes a los grandes objetos del reino de los valores:

«Pero todos los posibles valores se "fundan" en el valor de un espiritu personal e infinito y de un "universo de valores" que de aquel procede. Los actos que aprehenden valores son captadores de valores absolutamente objetivos, en tanto en cuanto se realizan "dentro de" ese espíritu, y los valores son valores absolutos, en tanto en cuanto acaecen dentro de ese reino" ${ }^{18}$.

Fundados en el valor último, personal y absoluto, es esencial a los valores su jerarquía en ese mundo, según el grado de cercanía al fundamento:

17 SCHELER, M. El formalismo en la ética material de los valores, Madrid, Revista de Occidente, 1941, tomo I, p. 103.

18 Ibidem, p. 140. 
"Un orden peculiar de todo el reino de los valores es que éstos poseen en su mutua relación una jerarquía, en virtud de la cual un valor es "más alto" o "más bajo" (superior o inferior) a otro, respectivamente. Esta jerarquía, como la diferencia de valores en "positivos" y "negativos", residen en la esencia misma de los valores, y no sólo es aplicable a los "valores conocidos" por nosotros. Ahora bien: mediante un acto especial de conocimiento del valor, llamado "preferir", se capta el hecho de que un valor es "superior" a otro" ${ }^{19}$.

A la jerarquía de valores, corresponde una jerarquía de estratos de la vida afectiva; entre ambos existe un riguroso paralelismo funcional. Scheler describe pormenorizadamente los grados en la jerarquía de los valores y sus correspondientes estados afectivos. Entre ambos existe paralelismo, pero no están mutuamente condicionados. La esfera de los valores tiene su autonomía como también la del sentimiento, o sea, la de los estados afectivos. Idealmente están una frente a otra, pero la esfera de la intencionalidad emocional se abre al influjo de la de los valores procurando hacerlos suyos.

El mundo de los valores se presenta estructurado en relaciones de superioridad e inferioridad ${ }^{20}$. Y es importante ver el lugar que ocupan los valores vitales. Este rango de los valores expresa el concepto total de la filosofía de Scheler encaminada a exaltar la vida del espíritu y del hombre como ser psico-físicoespiritual.

El rango inferior lo ocupan los valores de lo agradable y lo desagradable. Estos se presentan así en relación con la organización del ser psicofísico:

"Resalta en primer lugar, como una modalidad acusadamente delimitada, la serie de lo agradable y lo desagradable (es citada ya por Aristóteles). Le corresponde la función sentimental sensible (con sus modos, goce y sufrimiento), y, de otra parte, corresponden a esta serie de valores los estados afectivos de los "sentimientos sensoriales": el placer y el dolor sensible»"

Estos son los valores de cosa frente a los valores vitales y espirituales. Pero esto no supone que sean relativos, sino que son también aprióricos y se ofrecen al sentimiento puro que corresponde a la vida afectiva sensible. Los esta-

19 Ibidem, p. 129.

20 Góngora Perea, C., O.C., p. 90.

21 SCHELER, M. El formalismo en la ética...I, p. 151. 
dos emocionales correspondientes son el placer y el dolor. Lo agradable y lo desagradable son los valores característicos de la capacidad más baja de la vida emocional.

Los valores vitales son los que ocupan el rango siguiente en escala ascendente; suponen el valor de la vida como una esencia y una cualidad extratemporal. Y sus valores consecutivos son el bienestar y la prosperidad. Los estados afectivos que les corresponden son los sentimientos de expansión vital, tales como la soledad, la enfermedad, la vejez, la juventud, el miedo, cólera, audacia, etc.:

"Los valores vitales constituyen una modalidad axiológica íntegramente independiente que no puede ser reducida a valores de lo agradable y útil, ni tampoco, en modo alguno, a valores espirituales. El desconocimiento de este hecho lo reputamos como defecto fundamental en todas las teorías éticas precedentes» 22 .

Scheler se está refiriendo en este texto sobre todo a Kant que pasó por alto en virtud de un falso dualismo la especificidad de los valores vitales; para el sólo cabían los sensibles y los espirituales. De aquí se deduce que los valores vitales no son propios tan sólo de los hombres, sino también de los animales y las plantas, es decir, de todos los seres vivos. Por otra parte, estos valores no son propios de las cosas, como son los valores de lo agradable y lo útil. Los seres vivos no son cosas ni tampoco meramente cosas corpóreas: representan una última clase de unidades categoriales antes de los valores espirituales:

«El motivo último de la desconsideración de la especie peculiar de esta modalidad es el desconocimiento del hecho que la "vida" constituye una esencialidad auténtica y no un concepto empírico general que abarca simplemente las "notas comunes" a todos los organismos terráqueos en un tipo" ${ }^{23 .}$

El rango superior lo ocupan los valores espirituales que se presentan con un carácter especial y que exigen el sacrificio tanto de lo agradable como de lo vital. A la intuición de estos valores corresponden los estados emocionales de la alegría y tristeza espirituales, estimación y reprobación, etc.: 
"Los valores espirituales incluyen ya en el modo de ser dados una separación e independencia peculiares frente a la esfera total del cuerpo y el contorno, y se manifiestan como unidad también en la manifiesta evidencia de que los valores vitales "deben" sacrificarse ante ellos. Los actos y funciones en que los captamos son funciones del percibir sentimental espiritual y actos del preferir, amar, odiar, espirituales, que se diferencian de las funciones y actos vitales sinónimos ya fenomenológicamente, como también por su especial legalidad (irreductible de nuevo a cualquier tipo de legalidad biológica)" ${ }^{24}$.

El lenguaje de Scheler no puede ser más explícito respecto a la relación entre vida y espíritu referidos esta vez a sus respectivos campos axiológicos. Los valores vitales son preferidos a los utilitarios, de lo agradable y desagradable; la preferencia de éstos frente a aquéllos es la enfermedad del utilitarismo moderno. Pero, a su vez, los valores vitales deben ser sacrificados a los espirituales que suponen un orden de realidad cualitativamente diferente y superior a aquéllos. Es lo que ha hecho el naturalismo en sus diversas versiones incluido el vitalismo. Dentro de este campo, Scheler distingue los valores estéticos, los morales y científicos. Después añade un cuarto y último rango que son los valores religiosos que tienen una condición particular y es que se muestran en un objeto que es dado en la intuición como objeto absoluto: lo divino.

5. El problema desde el punto de vista psicológico

\section{a) La simpatía}

El punto anterior despejó las relaciones de lo vivo y lo espiritual en el ámbito axiológico, pero dejó a un lado los estados afectivos correspondientes a cada uno de los grados de los valores. Si el tratamiento de los valores, lo hizo en $E l$ formalismo en la ética, el de los estados afectivos correspondientes a éstos lo llevó a cabo de modo encomiable en Esencia y formas de la simpatía. Scheler aborda ahora la afectividad que tiene por contenido el flujo de lo vivido. Este tema es uno de los ejes de la filosofía scheleriana por las implicaciones éticas que conlleva. El tema lo habían puesto en circulación los moralistas ilustrados 
sobre todo los ingleses; y la ética de la simpatía se convirtió en una ética típica de la burguesía ${ }^{25}$. La simpatía era objeto de los juicio más dispares. Para Schopenhauer era el sentimiento moral por excelencia ${ }^{26}$; otros, como Nietzsche, vieron en ella algo decadente y antivital cuya desaparición era necesaria para el progreso ${ }^{27}$; de la misma forma pensaban los defensores de la naturaleza egoísta del hombre, como Hobbes, que entendían que su erradicación era necesaria para el fortalecimiento del hombre. En todo caso la valoración de la simpatía fue uno de los ejes de la filosofía vitalista.

Scheler delimita bien el sentido de esta palabra para aclarar su postura. Lo genuino de la simpatía es el reconocimiento de otro como algo autónomo e independiente de mí ${ }^{28}$. A partir de aquí, desecha los fenómenos concomitantes a la compasión que no pueden confundirse con ésta y que son fundamentalmente dos: el contagio y la identificación afectiva. El contagio se caracteriza por la reproducción, en un sujeto, de los sentimientos ajenos que son experimentados o vividos como propios. En ellos tiene lugar una reproducción subconsciente de los estados afectivos ajenos:

«El proceso del contagio tiene lugar involuntariamente. Peculiar a este proceso es ante todo el tener la tendencia a retornar de nuevo a su punto de partida, de tal suerte que los sentimientos correspondientes crecen en avalancha, por decirlo así. El sentimiento surgido por contagio contagia a su vez por el intermedio de la expresión y de la imitación de suerte que también crece el sentimiento contagioso; éste contagia a su vez, etc. ${ }^{29}$.

Estos fenómenos no tienen que ver con la simpatía. Como tampoco el sentimiento de identificación afectiva o unidad vital. En ella se efectúa la identificación de un yo psíquico con otro yo:

«Sólo un caso más intenso - por decirlo así, un caso límite del conta-

25 SMITH A. Teoría de los sentimientos morales, México, 1941, p. 46 y ss.

26 SCHOPENHAUER, A. El mundo como voluntad y representación, Buenos Aires, Aguilar, 1960, tomo III, p. 85 y ss., y Sobre el fundamento de la moral Madrid, La España Moderna, p. 197.

27 Nietzsche, F. El Anticristo, en Obras completas, Madrid, Aguilar, 1966, tomo IV, p. 462 y ss.

28 SCHELER, M. Esencia y formas de la simpatia, p. 25.

29 Ibidem, p. 33. 
gio- es finalmente la genuina unificación afectiva (o identificación) del yo propio con un yo individual ajeno. Es un caso límite en tanto que aquí, no sólo se tiene un determinado proceso afectivo ajeno inconscientemente por un proceso propio, sino que se identifica literalmente el yo ajeno (en todas sus actitudes fundamentales) con el yo propio. También aquí es la identificación tan involuntaria como inconsciente» ${ }^{30}$.

Scheler distingue dos clases de identificación afectiva, la ideopática, cuando el yo se identifica consigo mismo y la heteropática, cuando se identifica con la vida de otro yo. Y de ésta aduce Scheler nueve clases diferentes que van desde la afectividad de los pueblos primitivos hasta la identificación mística orgánica, sexual, etc. En todas ellas se produce un aniquilamiento completo del yo propio en un sentimiento de unidad vital con otro yo. Este sentimiento conduce al de la unidad metafísica de la vida en general. Pero tal unificación afectiva es así el medio de ingreso en la esfera exclusivamente vital, mientras que los actos intencionales, que son estrictamente personales y suponen comunión de personas, constituyen la entrada al mundo espiritual:

"La determinación que acabamos de hacer del único "lugar" posible de la unificación afectiva dentro de la constitución del hombre nos será de importancia para juzgar toda la serie de interpretaciones metafísicas que se han dado de los hechos de la simpatía. Me refiero a las llamadas interpretaciones "monistas" (Hegel, Schelling, Schopenhauer, von Hartmann, Bergson, Driesch, E. Becher). No van a ser impugnadas ni admitidas aquí. Pero sí se puede inferir de lo encontrado hasta ahora que sólo tienen sentido en la esfera de lo vital (es decir, allí donde se concluye la existencia metafísica de una "vida" supraindividual en todo lo viviente, de una protoentelequia en todos los entes organizados vitalmente), pero que jamás pueden dar ocasión para admitir un principio espiritual, uno e idéntico del mundo, como idénticamente activo en todos los espíritus finitos» ${ }^{31}$.

El fenómeno de la identificación afectiva no es pues un fenómeno espiritual y de él no puede deducirse un principio espiritual uno e idéntico del mundo. Una vez más Scheler delimita el campo de la vida y del espíritu.

$30 \quad$ Ibidem, p. 35.

31 Ibidem, p. 58. 
Donde si se da una actividad espiritual es en la simpatía propiamente dicha, la simpatía intencional, o sea, el acto mediante el cual, el sentimiento ajeno, como tal, se ofrece al sentimiento propio siendo de este modo aquél vivido en común por dos personas. Se realiza una penetración de un ser espiritual en otro lo cual significa un verdadero trascender la esfera individual de la vida. El fenómeno de la simpatía intencional presupone pues la oposición de dos sujetos o personas cuyo vivir afectivo mutuo es aprehendido en el sentimiento. He aquí las propias palabras de Scheler definiendo la simpatía intencional:

“Es, en efecto, un sentir el sentimiento ajeno, no un mero saber de él o simplemente un juicio que dice que el projimo tiene tal sentimiento; pero no es un vivir el sentimiento real como un estado propio; al vivir lo mismo que otro aprehendemos afectivamente además la cualidad del sentimiento ajeno - sin que éste transmigre a nosotros o se engendre en nosotros un sentimiento real e idéntico-" 32 .

La simpatía es pues un fenómeno reactivo por el que abordamos positivamente un estado anímico ajeno sin hacerlo propio. Así pues en ella hay un sentimiento ajeno de alguien reconocido como tal y una reacción afectiva por la que se apropia ese sentimiento manteniéndose clara la distinción de ambos. Y es un sentir, no un conocer. Scheler distingue tres clases de simpatía: la simultánea y directa identificación en un mismo sentimiento, la simpatía intencional reproductora y la comprensión emocional.

Antes de abordar el tema del amor como la más alta expresión de la intencionalidad emocional, Scheler hace una síntesis de fundamentación de los diversos fenómenos empáticos en orden a esclarecer el amor. La identificación afectiva es el fundamento de la simpatía. Ésta es el fundamento del amor del hombre. Y, a su vez, el amor del hombre es el fundamento del amor acosmístico a la persona y a Dios ${ }^{33}$.

\section{b) El amor}

El tema del amor en la filosofía de Scheler es capital; quizá sea el que dé la última clave sobre la vida emocional, la ética y el personalismo. Dupuy la cali- 
fica de filosofía del amor personal ${ }^{34}$. Lo primero que hace Scheler a este respecto es distinguirlo de la simpatía, pues el error de identificar ambos está en la base de las éticas de la simpatía, sobre todo la inglesa. En primer lugar, la simpatía es una tendencia que, como todas, se calma con la posesión de su objeto, mientras que el amor es algo esencialmente dinámico que se dirige a los objetos en cuanto valiosos y que no se calma nunca, sino que se despliega nuevamente con cada paso conquistado en busca de nuevos horizontes de valor cada vez más altos. El amor pues está referido a un objeto en cuanto valioso, la simpatía no. Pero lo fundamental es que el amor es espontáneo, mientas la simpatía es reactiva:

"Pero ante todo es el amor un acto espontáneo y lo es incluso en el "amor recíproco", como quiera que éste se halle fundado. Por el contrario, es todo simpatizar una conducta reactiva. Sólo se puede, por ejemplo, tener simpatía por seres sim-patizantes, mas el amor está totalmente libre de esta limitación” ${ }^{35}$.

El amor es por tanto, como relación esencial, cualitativamente superior a la simpatía por lo cual ésta es más amplia y menos valiosa que aquél.

Visto en sí mismo, el amor es la más alta forma de intencionalidad emocional; $y$, aunque tratar de definirlo con exactitud, es una empresa valdía, Scheler lo describe, mas que lo define:

«El amor es el movimiento en el que todo objeto concretamente individual que porta valores llega a los valores más altos posibles para él con arreglo a su destino ideal; o en el que alcanza su esencia axiológica ideal, la que le es peculiar» ${ }^{36}$.

Por el amor, el objeto amado llega a los valores más altos conforme a su destino ideal. El amante quiere que el ser amado llegue a su plenitud y contribuye a ello en cuanto puede. $Y$ en este movimiento no hay reposo, pues el mundo de los valores que se quiere para el ser amado es inagotable. El

34 Dupuy, M. La philosophie de Max Scheler. Son évolution et son unité, Paris, PUF, 1959, p. 719.

35 SCHELER, M. Esencia y formas de la simpatia, p, 181.

36 Ibidem, p. 218. 
amor se dirige a cualquier objeto individual concreto, es decir, está abierto a todos los seres y no sólo al hombre; aunque es cierto que a éste se dirige de manera primaria pues el hombre es individuo por excelencia portador de valores o sea, es persona. Pero el amor se dirige propiamente a seres individuales concretos, porque no tiene sentido el amor, propiamente dicho, a ideales o valores generales. El amor pide la realiżación del valor en un objeto concreto.

Y es justamente en la clasificación de las diversas formas de amor donde aparece la distinta contribución de la vida y el espíritu aunque se plasmen en una misma conducta:

"Respondiendo a la fundamental división de todos los actos en actos vitales o del cuerpo, actos psíquicos puros o del yo y actos espirituales o de la persona, también el amor y el odio se nos presentan bajo tres formas de existencia: el amor espiritual de la persona, el amor psíquico del individual yo y el amor vital o pasión. Bien que los actos vitales, psíquicos y espirituales sean ya en sí diversos como actos y sean vividos diversamente (y sólo con respecto a sus sujetos) están esencialmente vinculados a estos sujetos, el "cuerpo", el "yo" y la "persona". Al mismo tiempo se hallan estas formas de actos emocionales también esencialmente vinculados a determinadas especies de valores como a sus correlatos noemáticos. Los actos vitales a los valores de lo "noble" y "lo vulgar" o "vil", los actos psíquicos a los valores del conocimiento y de lo bello (valores culturales); los actos espirituales a los valores de lo santo o sagrado (y profano)" ${ }^{37}$.

Scheler, antes de abordar el amor vital describe el «humus» en que aquél se nutre, es decir, examina la relación del amor con el impulso ${ }^{38}$. ¿Se necesitan ambos y mutuamente? ¿Cómo se relacionan y hasta qué punto dependen? Aquí aflora la típica problemática de Scheler en el sentido de que el espíritu recibe la fuerza de los impulsos, pero es irreductible a ellos, por mucho que quieran desmentirlo las diversas teorías naturalistas que van desde el evolucionismo hasta Freud. He aquí las propias palabras de Scheler:

37 Ibidem, p. 225-226.

38 SuANCES MARCOS, M. «El amor y sus fenómenos concomitantes», Studium, XVI (1976), p. 133. 
«Un acto de amor se realiza en una organización biopsíquica dada allí y sólo allí donde existe también un movimiento impulsivo hacia la misma esfera de valor hacia la que apunta el movimiento del amor" ${ }^{39}$.

Por tanto, el sistema de impulsos es positivo para suscitar el acto de amor y para la elección y orden de elección de objetos, pero no para el acto de amor y su contenido. Dicho de otra manera, el impulso da vida y colorido a los objetos del amor; pero no produce éste sino que sólo lo limita y selecciona.

Dentro de los impulsos, Scheler toca preferentemente el impulso sexual como foco de vitalidad. Algunos, como Lipps, han intentado hacer del amor sexual un combinado de simpatía psíquica e impulso sexual no electivo. Sería de esta forma un amor tan indiferenciado como aquel que tenemos a los que nos alimentan cuidan, defienden... que se resume en una combinación de todos estos elementos que dan un tono específico al amor vital. Frente a eso, Scheler afirma que el amor sexual no representa ninguna combinación de esos amores, sino una especie particular que es la más céntrica del amor vital en general, que practica una elección entre los objetos que se le presentan y que prefiere una vida noble, floreciente y vigorosa:

"Aun cuando pueda no tener lugar una individualización absoluta del amor sexual, tal que se dirija a un ser sólo y sólo en él se satisfaga, sin la adición de una aprehensión del yo individual ajeno en un acto de amor espiritual independiente de la esfera sexual, aun sin la adición de esta aprehensión, es el amor sexual ya "amor" y no un mero impulso genérico, y es también capaz de llevar a cabo por sí una elección entre los fenómenos contrarios que se remonta muy por encima de un impulso sexual genérico y ciego" ${ }^{40}$.

El amor sexual, en la esfera vital, es el amor puro y simple. Dentro del sistema de los impulsos vitales y sus correspondientes movimientos de amor, el impulso y amor sexual es el fundamental como viera Freud. Los demás impulsos y amores reciben su dinamismo de éste. Cualquier perturbación de este impulso impide la entrega al resto de los valores vitales y embota las restantes formas del sentimiento vital. Por tanto el amor sexual no es una especie más de amor vital, sino la base y fundamento de las demás.

39 SCHELER, M. Esencia y formas de la simpatia, p. 245.

40 Ibidem, p. 266. 
Pero, a pesar de su función especial y del puesto central que ocupa en la esfera vital, el amor sexual no excede ésta y, aunque esté impregnado de amor espiritual, nunca llega a superar la esfera vital. Aquí Scheler se desmarca tanto del pansexualismo freudiano como del vitalismo:

"El amor sexual, aun en sus más nobles y más puras manifestaciones, pertenece radical $e$ indeclinablemente a la esfera vital del hombre, a la interna y externa, aun cuando pueda unirse a veces con él la amistad e incluso el amor metafísico a la persona individual. Pero como función psíquica vital jamás podrá llegar a ser el amor sexual un valor propio supravital al que estuviera dado y fuese lícito tomar a su servicio la totalidad de la vida. Lo único que puede llegar a ser, incluso en su más alta forma concebible, es la más fina flor y la verdadera cima, la culminación, la corona de la vida del hombre en cuanto ente vital" 41 .

Pero basta que el amor sexual sea tal y tenga su propio valor para que no pueda ser puesto al servicio del placer, ni de la reproducción, ni de cualquier otro fin. La cima cualitativa de la vida orgánica no puede ser sacrificada al poder, ni a la utilidad, etc. Ella tiene su propio sentido.

Max Scheler se detiene mas tarde en la complección de la teoría del amor. La segunda clase de amor, superior al vital, es el amor psíquico que tiene por sustrato el yo. Se dirige al individuo en un sentido más estricto que el amor sexual, en un sentido único e irrepetible. Este amor al alma individual puede aparecer en muchas formas: amistad, matrimonio...y se mantiene incólume en medio de las intermitencias de la vida. Lo distintivo de este amor es la conciencia y se podría definir formalmente por la categoría de la vivencia. El amor espiritual a la persona sería una profundización de este amor psíquico. Es el amor sagrado cuyo depositario es la persona y cuyo correlato son los valores sagrados. Si todo amor se refiere a un objeto con autonomía propia, el amor a la persona ocupa el puesto superior de la escala de objetos pues la persona es algo absoluto que no puede ser medio de nada. En definitiva, todos los demás valores deben ser sacrificados a la persona. De aquí que Scheler trate por largo y tendido de demostrar que tanto el amor psíquico como el personal no son fruto de la sublimación de impulsos, sino que son una cualidad nueva irreductible a éstos; es decir, son absolutamente originales:

41 Ibidem, p. 151. 
"Si la teoría naturalista viese los fenómenos del amor sacro y del amor psíquico, al punto vería también que es imposible derivarlos de ningún hecho perteneciente a la esfera y amor vitales y hacerlos comprensibles por él. Pero éste es precisamente el error fundamental de ésta y otras tesis de la teoría naturalista: su actitud toda la hace ciega para el hecho de que en el curso de la evolución de la vida y de la Humanidad aparezcan y puedan aparecer actos y cualidades completamente nuevos ${ }^{42}$.

Estas cualidades aparecen de una forma esencialmente súbita y no pueden ser consideradas como transformaciones meramente graduales de las antiguas como puedan serlo las referidas a la organización corporal de los seres vivos.

\section{c) La muerte}

Quedaría incompleto este punto si no se abordara un tema esencial para los seres vivos en los que, por fuerza, ha de tomar parte el espíritu humano: la muerte. En un primer momento, Max Scheler se detiene a mostrar cómo la muerte está esencialmente ligada a la vida. Occidente se ha empeñado en reprimir la idea de la muerte y eso hace también que tenga una visión defectuosa de la ciencia misma de la vida y emplee la fuerza de ésta en orientaciones contrarias a ella, por lo que la vida humana queda empobrecida en su conjunto.

La idea más corriente de la muerte considera ésta como resultado de una experiencia exterior: vemos que mueren todos los seres vivos. Pero esta idea es rechazable: el hombre ha de aplicarse a si mismo la idea de la muerte y, aunque fuese él solo, llegaría a conocer ésta por si mismo. El envejecimiento, la enfermedad y el sueño son experimentados por el hombre y estos son signos premonitorios de la muerte. Pero no son suficientes, ya que la suma de ellos no es la muerte y podemos hacernos a la idea de que la vida podría proseguir aunque fuera en condiciones precarias. La idea de la muerte es distinta de esos fenómenos; es algo nuevo y peculiar que pertenece a la conciencia vital:

"Pero si se separa con rigor la "idea y esencia” misma de la muerte de todos estos conocimientos que sólo la experiencia suministra, se encontrará que esta idea pertenece a los elementos constitutivos, no sólo de nuestra conciencia, sino de toda conciencia vital ${ }^{43}$.

42 Ibidem, p. 238.

43 SCHELER, M. Muerte y supervivencia, Madrid, Revista de Occidente, 1934, p. 23. 
La estructura misma de la vida es un proceso de pasado, presente y futuro; en cada momento indivisible de ese proceso sentimos algo que escapa y algo que se acerca. En cada uno de esos tiempos hay una dirección que es un continuo apurar lo vivible; esa dirección es un crecimiento de la extensión del pasado a costa del futuro. En esa experiencia va incluida la vivencia de la muerte, pues aunque no percibiéramos el envejecimiento, al conocer que nuestra dimensión de futuro se va acabando irremisiblemente hasta llegar a cero, ahí se nos daría la muerte natural. Esto aparte de nuestro temor o esperanza ante la muerte. Por tanto, la muerte no se halla al final del proceso, sino que al final se encuentra sólo la realización de la esencia de la muerte; ésta es, por consiguiente, una a priori del proceso biológico. En definitiva, la muerte es algo esencial y no contingente para el ser vivo:

"La muerte no es, por tanto, simplemente una parte empírica de nuestra experiencia, sino que es de esencia de la experiencia de toda vida, inclusive de la nuestra propia, el hallarse dirigida hacia la muerte. La muerte pertenece a la forma y a la estructura únicas en que nos está dada cualquier vida, la nuestra como otra cualquiera, y esto desde dentro $y$ desde fueras ${ }^{44}$.

Siendo la idea de la muerte algo esencial, cuando sentimos ésta como algo contingente es porque alguna causa especial la ha eliminado del campo natural de la conciencia. Es aquí donde Scheler inserta una severa crítica a la cultura occidental por haber empleado todas sus técnicas de propaganda y formas de vida para eliminar la idea de la muerte. El morir pues pertenece a la vida y, sea cual sea la forma en que la muerte sobrevenga, el acto de «morir su muerte» es el último acto del ser vivo. Pertenece a la esencia de la muerte que el ser vivo realice el acto de morir.

¿Cómo encara el espíritu la experiencia de la muerte? ¿Qué implicaciones tiene en ella? La idea de la inmortalidad o supervivencia no es una bella huida ni una represión de la idea de la muerte, sino la aportación del espíritu realizada en la persona humana. El hombre es el único ser vivo que reclama la supervivencia justamente por ser también espíritu, por ser persona. La primera condición para la supervivencia después de la muerte es la muerte misma: sólo si se ha realizado la sumisión espiritual a la muerte, es posible la creencia en la supervivencia. Scheler, igual que Sócrates en este punto, renuncia a la 
demostración de la inmortalidad. Uno y otro dirán que la inmortalidad es objeto de experiencia inmediata y por tanto no tiene demostración; además, ser inmortal es algo negativo y por tanto igualmente indemostrable. Para resarcirse de este carácter negativo, Scheler habla más bien de supervivencia de la persona que de inmortalidad del alma. En caso de tener que probar la supervivencia - se pregunta Scheler- ¿a quien le tocaría? Aunque logre mostrar que existe una independencia esencial de la persona respecto a la vida orgánica, y que hay leyes esenciales para sus actos, intenciones, etc., independientes de las leyes esenciales de los seres vivos, jamás podrá probar que con el último acto vital, la muerte, no dejará también de existir la persona; a pesar de la independencia de la persona respecto a su ritmo vital, pudiera ser que ésta dejara de existir cuando sobreviene la muerte. Pero la muerte no es una razón suficiente para admitir eso y, quien lo afirme, está obligado a probarlo. De igual modo cabe preguntarse si la muerte física del otro supone la eliminación de su persona. La admisión de la existencia de otra persona no se funda ni en un razonamiento sobre su cuerpo, ni en un acto de vinculación afectiva a su yo, sino en fenómenos de expresión que nos están dados; pero, una vez llegados a esa persona, ella es independiente de la existencia ulterior de semejantes fenómenos. Por consiguiente, la desaparición de esos fenómenos por la muerte no prueba la inexistencia de la persona; ésta es invisible:

«El que la persona sea invisible no significa nada. Invisible es también en cierto sentido la persona espiritual cuando hablo con ella y cuando se expresa. El que no la veamos después de la muerte quiere decir muy poco, puesto que nunca puedo verla con los sentidos. El que los fenómenos de expresión desaparezcan después de la muerte es una razón tan sólo para que yo no pueda entender ya a la persona; pero no una razón para suponer que no exista" ${ }^{45}$

No está escrito que la persona deba perdurar, pero su falta de expresión no es motivo para que no perdure.

Llegados a este punto, Scheler distingue con toda claridad la doctrina de la eternidad del espíritu y la de la supervivencia de la persona. Mientras la primera resulta clara y ya los griegos la vieron con nitidez, la segunda se muestra sólo negativamente, es decir, la muerte corporal no es razón para que la 
persona deje de existir. Respecto a la eternidad del espíritu, dice Scheler que éste realiza actos independientes respecto al proceso vital. La captación del contenido de la idea $2+2=4$ supone un acto independiente del ritmo vital aunque el sujeto lo realice cuando llega al uso de la razón. Igualmente las leyes que rigen las verdades o falsedades no se siguen de leyes vitales. Pero de ahí no se desprende que esos actos supongan la supervivencia de la persona que los sustenta:

"Las leyes que rigen el sentido y la conexión objetiva de mis afirmaciones, su diferencia en verdaderas y falsas, no es algo que se sigue de ninguna posible ley esencial de la vida, ni de las reglas de la biología científica. Es verdad que en estos actos yo trasciendo de todo lo que es aún relativo a la vida, y puedo decir que en tales actos mi espíritu toca a un dominio, a una esfera de unidades de sentido intemporales y eternas. Pero no puedo decir más. Que los actos que yo realizo, o que mi persona que los realiza, sobrevivan también cuando yo dejo de vivir, no se sigue en manera alguna de la conexión esencial entre la idea de un acto y un objeto" ${ }^{46}$.

Respecto al segundo punto, la supervivencia, Scheler advierte, como condición previa, que los hechos espirituales no dependen de los psicofísicos. Y compara la relación entre ambos con el pianista y el piano. La persona se comporta respecto a la totalidad de los procesos corporales y psíquicos como el pianista respecto al piano. $Y$ en esta línea Scheler señala la distinción entre la vivencia inmediata de la vida y el ser objetivo de la vida vivida; y muestra la experiencia de cómo la persona trasciende los actos psicofísicos del percibir, recordar, etc., ampliando sus contenidos, dándolos riqueza cualitativa, recreándolos y traspasando sus límites espacio-temporales:

«Pero mi espíritu rebasa estos límites en dos direcciones: en la actitud del recordar me introduzco en el pasado $y$, trozo por trozo, aparece ante mi mirada espiritual el mundo pasado; análogamente, esperando, me encuentro espiritualmente con los contenidos de mi futuro. Ya Platón en el Fedón se fijó en el hecho admirable del recuerdo y extrajo del él profundas intuiciones para el problema de la supervivencia" ${ }^{47}$.

46 Ibidem, p. 77-78.

47 Ibidem, p. 88. 
Esta riqueza de la persona postula una esencia irreductible a los estados corporales a pesar de su relación con ellos:

«En todos estos casos encontramos el mismo hecho fundamental constitutivo del espíritu, de su ser y de su vida. Unida a estados corporales mudables y a sus correlatos objetivos en el cuerpo, para todo lo referente a la selección especial de los contenidos de las intenciones de la persona, sin embargo, la esencia de esta persona y de estas intenciones, su sentido y el contenido esencial que en cada caso poseen, no son jamás resolubles en estados corporales, o sensaciones, y derivados genéticos suyos, reproducciones, etc. Nuevamente, la persona espiritual misma y su modo espiritual son infinitamente más ricos en esencia que todas sus posibles intenciones” ${ }^{48}$.

Si es esencial a la persona trascender los límites del cuerpo y sus estados, la pregunta insoslayable cae por su peso: ¿qué es lo esencial de la persona cuando el cuerpo muere?:

"A la esencia de la persona pertenece exactamente lo mismo que lo que pertenecía cuando el hombre vivía —-por tanto, nada nuevo-, a saber: así como durante la vida trascendían sus actos de sus estados corporales, así también ahora trascienden de la destrucción de su cuerpo. Y solamente este flotar, este perdurar y trascender de este acto dinámico que pertenece a su esencia, esto sólo, es lo que en el morir debe constituir la plena vivencia y el ser de la personan ${ }^{49}$.

La persona se vive pues a si misma como sobreviviendo todavía, o sea, es y vive independientemente respecto a su cuerpo. Con esto Scheler cree haber agotado el problema. Pero es parco con respecto a los resultados; no sabemos si la persona continúa existiendo o no después de la muerte. Hay que creer que continúa porque no hay motivo para lo contrario, ya que se cumplen con evidencia las condiciones de su esencia. Aquí se ve la distinta dirección de la vida y el espíritu: aquélla, respecto a la naturaleza, va de una gran libertad a la máxima ligazón que coincide con la muerte; el espíritu en cambio va al revés: de la dependencia de las necesidades vitales a la libre entrega al contenido puro de los valores.

\footnotetext{
48 Ibidem, p. 91.

49 Ibidem, p. 94.
} 


\section{El problema desde el punto de vista cultural}

Para terminar el tratamiento sistemático de la relación entre vida y espíritu Scheler aborda el tema desde la perspectiva de la cultura. El hombre, biológicamente, ha llegado a su plenitud y por ahí no cabe ya evolución alguna; ésta ha de venir exclusivamente por la actividad del espíritu basada precisamente sobre ese material vivo del instinto:

"Puede entenderse la cuestión relativa al porvenir del hombre — cuando se trata del destino de éste en general- ya biológicamente o aludiendo más bien a lo espiritual. Hay, pues, que elegir desde luego, al mismo tiempo de plantearse el problema entre estas dos nociones: si el hombre, como organización biológica, tiene aún ante sí un margen de futuro, o si en lo esencial, está ya orgánicamente "acabado", y su futuro, por consiguiente, sólo en cuanto al espíritu ha de enjuiciarse. Personalmente, estoy convencido (con Weissmann) de que el hombre, como organismo, está acabado en lo esencial; más aún: que entre los seres orgánicos es el más fijado de los tipos. Hablar de un "superhombre" orgánico paréceme una fantasía» 50.

Para Scheler, el hombre, biológicamente, es un callejón sin salida y la evolución se detuvo en él para potenciar su espíritu produciendo así la cultura y la historia. El progreso humano será cultural, no biológico. Ésta es la diferencia esencial entre el hombre y el animal. Éste sigue ciegamente sus instintos sin posibilidad de cambio. El hombre por su espíritu, es decir, por su razón y su libertad, es un ser abierto y plástico, cuya vida va configurando libremente tanto individual como colectivamente camino de una perfección sin límite.

En este sentido la cultura es el proceso subjetivo y objetivo de crecimiento del espíritu sobre la base de la vida que el hombre proyecta. Aquí es donde Scheler califica la cultura humana, en terminología hegeliana, como una automanifestación del espíritu divino en el hombre, o dicho de otro modo, una "deificación" por la ejecución de actos espirituales ${ }^{51}$. El hombre pues no es espiritualmente un "factum» sino una tarea luminosa que ha de ejercer sobre sí mismo y sobre la naturaleza. Esta es la humanización concebida por Scheler:

50 SCHELER, M. El porvenir del hombre en Metafisica de la libertad, Buenos Aires, Nova, 1960 , p. 109 y El saber y la cultura, pp. 33-34.

51 SCHELER, M. El saber y la cultura, p. 34. 
"En este sentido no puede hablarse del hombre como una cosa -ni siquiera como de una cosa sólo relativamente constante-, sino más propiamente de humanización, de un proceso eterno, siempre posible, que debe realizarse libremente en todo instante; hay sólo un devenir hombre, que no cesa ni en el tiempo histórico, a menudo con formidables recaídas en relativa animalidad" 52 .

La humanización y la deificación son dos nombres de un mismo proceso en el que, para Scheler, quedan involucrados tanto su sentido antiguo como cristiano. En este sentido, el ser del hombre trasciende los límites y el valor de la vida para llegar al ámbito del espíritu. Esta deificación del espíritu sobre la base de los impulsos vitales, que son los que le dan fuerza, ya que aquél, como tal, es impotente, es la esencia de la cultura y la justificación filosófica del sentido y valor de aquélla. Este proceso tiene dos caras como el anverso y reverso de una misma moneda: es una espiritualización de la vida y una vitalización del espíritu.

Llegado aquí, Scheler enfoca la cultura desde dos puntos de vista: como algo cumplido y como proceso. $\mathrm{Si}$ atendemos a lo primero, la cultura se presenta como una forma, una figura, un ritmo individual, peculiar de cada uno. Dentro de los límites propios de esa forma peculiar, se producen las actividades espirituales de la persona; así se configura el hombre entero:

«Cultura es, pues, una categoría del ser, no del saber o del sentir. Cultura es la acuñación, la conformación de ese total ser humano; pero no - como en la forma de una estatua o de un cuadro- aplicando el cuño a un elemento material, sino vaciando en la forma del tiempo una totalidad viviente, una totalidad que no consiste nada más que en fluencias, procesos, actos" 53 .

Esa totalidad viviente en la que se integran actos y procesos da lugar en Scheler a abordar el segundo punto de vista: la cultura como proceso. ¿Qué clase de proceso? La cultura nada tiene que ver ni con el acopio de conocimientos, ni mucho menos con la adquisición de aptitudes para el rendimiento profesional o la preparación para la lucha por la vida. La cultura no tiene

$52 \quad$ Ibidem, p. 37.

53 Ibidem, p. 19. 
finalidad externa; no es para algo, sino que es el desarrollo del hombre perfecto. Y aun en este punto, Scheler precisará que la cultura no es querer hacer de sí mismo una obra de arte; eso es un narcisismo que tiene por objeto el propio yo y su belleza. ¿¿Dónde está y en qué procesos se elabora la cultura?:

«En el proceso de su vida, dentro del mundo y con el mundo; en el diligente vencimiento de las pasiones y las resistencias, tanto propias como del mundo; en la acción y el amor, ya sea referido a las cosas, al prójimo o al Estado; en el duro trabajo que, al producir rendimiento, acrece, eleva y amplía las fuerzas y el propio yo; $y$, por último, en la intención de un autentico acto deificante, de aquel velle, amare in Deo, de aquel cognoscere in lumine Dei (como San Agustín y Lutero designaban este acto inmaterial de deificación), es donde se verifica y se cumple la formación de la cultura, de espaldas al simple propósito, al simple querer» ${ }^{54}$.

Sólo pues el que esté dispuesto a perderse a sí mismo por una causa noble que trasciende el yo es el que llega a la verdadera cultura. Mas adelante insiste Scheler - de acuerdo con una mentalidad muy germánica - en los medios para estimular la cultura como son la identificación con un modelo valioso de persona que gana nuestro amor y descubre nuestra verdadera personalidad. Sumergirnos en un hombre integral y generoso nos da la medida de nuestro valor. También la inserción en el «ethos» y valores más auténticos de la época que nos ha tocado vivir.

En este punto Scheler se emplea a fondo en la crítica a la cultura moderna occidental. Y un primer diagnóstico sobre ella es que no ha respetado el equilibrio entre lo vital y lo espiritual. La cultura verdadera está sometida tanto a las leyes de la vida como a las objetivas o transvitales. Como diría Ortega, tenemos dos imperativos; el vital y el cultural; la vida ha de ser culta y la cultura tiene que ser vital. El desequilibrio de una de las dos lleva a la decadencia. La vida inculta es barbarie; la cultura desvitalizada es bizantinismo. Hay que preguntarse si la cultura occidental suscita las energías profundas de nuestra personalidad. Y con este criterio juzga Scheler la cultura europea tachándola de utópica, pero, sobre todo, de falta de vitalidad. ¿̨or qué? Porque Occidente ha preferido de forma unilateral el saber positivo, olvidándose del saber culto y de 
salvación; éste último ha sido cultivado, también de modo unilateral, por Oriente. De ahí que Scheler reclame en este sentido una necesaria nivelación entre Oriente y Occidente ${ }^{55}$. Al saber positivo sólo le interesa el dominio del mundo para intereses utilitarios u otros peores:

"El saber culto y el saber de salvación han pasado, en la historia última de Occidente, cada vez más a segundo término. Pero aun de ese saber de dominio y de trabajo sólo se ha cultivado una mitad durante dicho período: aquella parte que sirve a la dominación y gobierno de la naturaleza externa (sobre todo la inorgánica). En cambio, la técnica interna de la vida y del alma, es decir, el problema de extender hasta el máximo el poderio y el dominio de la voluntad, y por ella del espíritu, sobre los procesos del organismo psicofísico -en cuanto éste, como unidad rítmica del tiempo, obedece a leyes vitales-, quedó decididamente relegado a segundo término por el afán de gobernar la naturaleza externa y muerta (incluso lo que en el organismo es naturaleza muerta)» ${ }^{56}$.

El positivismo y el pragmatismo son a este respecto filosofías muy parciales que se han extendido de forma universal por Europa y América. Scheler compara en ese sentido nuestra cultura con la alejandrina en lo que a decadencia se refiere:

«Si contemplamos sucintamente los movimientos espirituales de nuestro tiempo, en su relación con la cultura y la ciencia auténticas, advertimos que, a pesar de los maravillosos triunfos de la ciencia, y en especial de las ciencias naturales, el cuadro de conjunto ofrece no pocos rasgos hondamente inquietantes. En mi Sociologia del saber, he hecho notar cómo la estructura científico-teórica y científico-sociológica de nuestra sociedad se aproxima cada vez más a la de la época alejandrino-helenística” ${ }^{57}$.

Pero hecho el diagnóstico, Scheler no se contenta con describir el mal; va a su raíz. ¿Cuál es ésta? La moderna cultura europea, a pesar de todo su oropel progresista, tecnológico y cientifista, está enferma. Debajo del lujo, del confort

55 SCHELER, M. El hombre en la etapa de nivelación, en Metafisica de la libertad, Buenos Aires, Nova, 1960.

56 SCHELER, M. El saber y la cultura, pp. 78-79.

57 Ibidem, p. 16. 
y de los descubrimientos tecnológicos, está un hombre cansado de vivir, atosigado por los artefactos que él mismo ha creado. Pero Scheler sigue profundizando en los motivos últimos de esa actitud y encuentra que, en el fondo del domino del mundo por parte del hombre, hay una actitud de odio hacia aquél. El mundo, en la época actual es objeto de domino y de lucro, no de amor y contemplación:

"El espíritu civilizador de la cautela, prudencia, preocupación, el sentido para la parte dominable del mundo se encuentra por lo tanto en absoluta oposición con el amor del mundo. Pues se trata de transformar el mundo $\mathrm{y}$ remodelarlo de acuerdo a finalidades prácticas y humanas. Esto hace necesariamente que la actitud anímica básica frente a las cosas sea una relación hostil y desconfiada, en la que se produce la actividad civilizadora. De ahí también que toda cosmovisión filosófica que brotó del amor hacia el mundo se encuentra en total oposición con la cosmovisión nacida del espíritu civilizador...

La civilización moderna se apoya por lo mismo mucho más en el odio al mundo que en el amor al mundo. Sólo un mundo que en su núcleo es experimentado como "carente de sentido y de valor", como "valle de lágrimas", puede despertar al máximo el estímulo intensificado para el dominio que rige en el desarrollo de la civilización moderna. Este odio y esa negación del mundo llegaron a su paroxismo en el pragmatismo moderno" ${ }^{58}$.

Scheler coincide con Nietzsche en el diagnóstico de la civilización moderna: su fondo es odio al mundo. Pero continúa investigando y se pregunta por la causa de ese odio. En El resentimiento en la moral describe con maestría y minuciosidad la causa: se trata de una transmutación de valores que ha hecho la civilización moderna; ésta ha preferido los valores útiles a los vitales y la actitud que impregna esta mentalidad es el resentimiento. La rebelión de los esclavos, tan clamorosa en Nietzsche, se funda en ese resentimiento que consiste en preferir lo útil a lo vital; $y$ es que lo útil tiene sentido en tanto en cuanto ayuda a lo vivo, no a la inversa. Lo útil, como tal, es un medio para conseguir lo agradable: esto es más fundamental, aquello es derivado. A su vez, lo agradable debe subordinarse a los valores superiores: vitales y espirituales. Pues bien, la civilización moderna ha preferido el trabajo útil al goce de lo agradable. Esto

58 SCHELER, M. El santo, el genio, el héroe, Buenos Aires, Nova, 1971, p. 86 y 88. 
representa claramente una discriminación de las funciones vitales:

"El ascetismo moderno se revela en el hecho de que el goce de lo agradable, a que se refiere todo lo útil, experimenta un progresivo desplazamiento - hasta que, finalmente, lo agradable queda subordinado a lo útil-. También aquí, el motivo que impulsa al hombre moderno, partidario del trabajo y de la utilidad, es el resentimiento contra la superior capacidad de goce, contra el arte superior para gozar; es el odio y la envidia contra la vida más rica, que engendra siempre una capacidad de goce más rica" 59.

Scheler cree que este modo de pensar, que es la esencia del capitalismo, es herencia de la tenebrosa mentalidad calvinista. El impulso moderno hacia el trabajo no es resultado de la afirmación del mundo y de la vida, sino fruto de una actitud hostil proveniente de la creencia de que el mundo y el hombre son intrínsecamente malos. Los trabajos de W. Weber y E. Troeltsch esclarecen esto. Así la mayoría de los hombres en la época actual trabaja por el sentimiento externo de un deber impuesto, no por el goce que el trabajo lleva consigo. El ideal del ascetismo moderno es producir el máximo de cosas útiles y agradables con un mínimo de goce ${ }^{60}$.

La más honda transformación actual es la subordinación de los valores vitales a los utilitarios. Esa es la causa de la expansión y triunfo del espíritu industrial y mercantil frente al artesano y contemplativo; es la preferencia de lo útil a lo noble. He aquí las propias palabras de Scheler:

«La inversión de la valoración se manifiesta, sobre todo, en que los valores profesionales del comerciante y del industrial, los valores de las cualidades con que este tipo de hombre prospera y hace negocios, son exaltados al rango de valores morales universalmente válidos y aun "supremos". Prudencia, rapidez de adaptación, intelecto calculador, inclinación hacia la "seguridad" de la vida y del tráfico universal y sin trabas, o las cualidades capaces de producir estas condiciones: espíritu de "contabilidad" en todas las cosas, de continuidad en el trabajo y la labor, ahorro, exactitud en el cumplimiento y cierre de los contratos: tales son ahora las virtudes cardinales a

59 SCHELER, M. El resentimiento en la morah p. 200.

60 SCHELER, M. Trabajo y ética en Amor y conocimiento, Buenos Aires, Sur, 1960, pp. 156157. 
las que se subordinan el denuedo, la valentía, la capacidad de sacrificio, la alegría en el riesgo, la nobleza del alma, la fuerza vital, el espíritu de la conquista, la indiferencia hacia los bienes económicos, el amor a la patria y la fidelidad a la familia, a la raza y al príncipe, la aptitud para dominar y regir, la humildad, etc.» ${ }^{61}$.

Como consecuencia de esto, la vida de un individuo o grupo se justifica por el provecho que obtiene; si no hay rendimiento, no se tiene derecho a vivir. Con ello, se pierde el valor propio de la vida. Así ésta deja de ser un fenómeno primario para ser considerada como un complejo de procesos mecánicos y psíquicos; eso fue lo que hizo Descartes. La organización vital es concebida mecánicamente como una suma de partes. Su unidad vendría dada por fuerzas físico-químicas aglutinadas desde fuera por un yo o alma, con lo cual se disuelve el principio de solidaridad. Scheler estudia detenidamente la proyección de este problema en el campo social afirmando que el individuo se desentiende del conjunto y que, en consecuencia, se disuelve la comunidad en beneficio de la sociedad contractual.

Hasta aquí han llegado las consecuencias del desprecio a los valores vitales. En esa misma línea y en coherencia con ella, la civilización actual menosprecia también los valores del espíritu, como se muestra en la falta de valoración y amor a la persona. La filantropía moderna es fruto del resentimiento que se dirige a la multitud y no a la persona concreta. Es este un roblema que Scheler analiza promenorizadamente en El resentimiento en la moral ${ }^{62}$

61 SCHELER, M. El resentimiento en la morah pp. 205-206.

62 Ibidem, p. 132 y ss. 